\title{
Caspase-2 (Nedd-2) Processing and Death of Trophic Factor- Deprived PC12 Cells and Sympathetic Neurons Occur Independently of Caspase-3 (CPP32)-Like Activity
}

\author{
Leonidas Stefanis, ${ }^{1,2}$ Carol M. Troy, ${ }^{1}$ Haiqing Qi, ${ }^{1}$ Michael L. Shelanski, ${ }^{1}$ and Lloyd A. Greene ${ }^{1}$ \\ Departments of ${ }^{1}$ Pathology and ${ }^{2}$ Neurology, Taub Center for Alzheimer's Disease Research and Center for Neurobiology \\ and Behavior, Columbia University College of Physicians and Surgeons, New York, New York 10032
}

We have previously shown that caspase-2 (Nedd-2) is required for apoptosis induced by withdrawal of trophic support from PC12 cells and sympathetic neurons. Here, we examine the relationship of caspase-2 processing and cell death to induction of caspase-3 (CPP32)-like activity in PC12 cells. Caspase-2 processing, at a site tentatively identified as D333, led to the formation of an $\mathrm{N}$-terminal $37 \mathrm{kDa}$ product. This processing correlated temporally with induction of caspase-3like activity. Agents previously shown to inhibit caspase-3-like activation, such as bcl-2 and the Cdk inhibitor flavopiridol, also acted upstream of caspase-2 processing. The general caspase inhibitors BAF and zVAD-FMK inhibited N-terminal caspase-2 processing. In contrast, the more selective caspase inhibitor DEVD-FMK inhibited the induction of caspase-3-like activity but did not affect caspase-2 processing or significantly suppress death in PC12 cells or sympathetic neurons. This indicates that caspase-3-like activity is not required for either caspase-2 processing or apoptosis in this paradigm. An antisense oligonucleotide to caspase-2 inhibited cell death but did not affect caspase-3-like activity, indicating that caspase-2 is not upstream of this activity and that activation of caspase-3like caspases is not sufficient for death. Thus, in our paradigm, caspase-2 processing and caspase-3-like activity are induced independently of each other. Moreover, although death requires caspase-2, caspase-3-like activity is neither necessary nor sufficient for death.

Key words: caspase; apoptosis; cell death; PC12; cell cycle; processing
Apoptosis is a form of cell death that is characterized by active participation of the cell in its own demise via the activation of a defined biochemical pathway. We and others have pursued the study of apoptosis in neuronal cells, with the expectation that it may provide insights into the way these cells degenerate in neurological diseases. To study the neuronal apoptotic pathways at a cellular level, we have used the model system of rat pheochromocytoma PC12 cells (Greene and Tischler, 1976). When PC12 cells are deprived of trophic support, they undergo rapid apoptotic death. NGF and other agents reversibly block such death (Greene, 1978; Batistatou and Greene, 1991; Rukenstein et al., 1991). This paradigm, along with cultured sympathetic neurons, serves as a model of neuronal cell death caused by loss of access to neurotrophic factors.

The protease family of the caspases, the mammalian homologs of the Caenorhabditis elegans death gene ced-3, is required for mammalian apoptosis (Yuan et al., 1993; Fraser and Evan, 1996). Based on sequence homology, the caspases can be divided into three subgroups: the interleukin- $1 \beta$-converting enzyme (ICE)like (caspase-1), the CPP32-like (caspase-3), and the Ich-1/ Nedd-2 (caspase-2) subfamilies (Fraser and Evan, 1996). We have

\footnotetext{
Received July 10, 1998; accepted Sept. 2, 1998.

This work was supported in part by grants from National Institutes of Health/ National Institute of Neurological Diseases and Stroke, March of Dimes Birth Defects Foundation, Muscular Dystrophy Association, Blanchette Rockefeller Foundation, American Parkinson's Disease Association, and the Amyotrophic Lateral Sclerosis Foundation. L.S. was supported by a grant from the Lucille P. Markey Trust. We thank Dr. Adriana Rukenstein for excellent assistance with cell culture. Correspondence should be addressed to Leonidas Stefanis, Departments of Pathology and Neurology, Taub Center for Alzheimer's Disease Research and Center for Neurobiology and Behavior, Columbia University College of Physicians and Surgeons, 630 West 168th Street, P\&S 15-401, New York, NY 10032.

Copyright (C) 1998 Society for Neuroscience $0270-6474 / 98 / 189204-12 \$ 05.00 / 0$
}

shown previously that caspases, and in particular caspase-2 (Nedd-2) (Kumar et al., 1994), are required in apoptosis induced by trophic deprivation in both PC12 cells and sympathetic neurons (Troy et al., 1996, 1997).

The caspases are cysteine aspartases that cleave their substrates at aspartate residues. It appears that to be activated, they need to be cleaved at aspartate residues and to form active heterodimers (Ramage et al., 1995; Xue et al., 1996; Yamin et al., 1996). This cleavage can be autocatalytic (Ramage et al., 1995; Xue et al., 1996; Yamin et al., 1996), performed by another caspase (Srinivasula et al., 1996; Xue et al., 1996), or, in some cases, by specific serine proteases, such as granzyme B (Darmon et al., 1995; Duan et al., 1996). This has led to the idea that a protease cascade may be instigated after the application of apoptotic stimuli (Enari et al., 1996; Fraser and Evan, 1996; Srinivasula et al., 1996). However, it is still unclear whether such cascades operate within cells after apoptotic stimuli. It was shown previously that caspase- 2 is processed, and presumably activated, within PC12 cells and sympathetic neurons after withdrawal of trophic support (Deshmukh et al., 1996; Stefanis et al., 1997; Troy et al., 1997). In the current work, we wished to examine potential upstream regulators of caspase- 2 processing and, in particular, to examine the relationship between caspase- 2 and the caspase-3-like activity that we have shown previously to be induced in PC12 cells after withdrawal of trophic support (Stefanis et al., 1996). Although a number of studies indicate that caspase-3 may be necessary for certain forms of apoptosis (Nicholson et al., 1995; Kuida et al., 1996; Woo et al., 1998), we have provided evidence in our paradigm that caspase-3-like activity can be partially dissociated from death when cells are treated with low concentrations of the caspase inhibitor zVAD-FMK (Stefanis et al., 1996). Our current 
data indicate that caspase- 2 processing occurs by a noncaspase3-like caspase, that caspase-3-like activation lies in a parallel pathway compared with that of caspase-2, and that caspase-2, and not caspase-3-like activity, is directly related to cell death in this model.

\section{MATERIALS AND METHODS}

\section{Cell culture}

PC12 cells were grown as described previously (Greene and Tischler, 1976; Rukenstein et al., 1991) on rat tail collagen-coated dishes in Roswell Park Memorial Institute (RPMI) 1640 medium containing 5\% fetal bovine serum and 10\% heat-inactivated horse serum (complete medium). Neuronally differentiated PC12 cells were grown for at least $12 \mathrm{~d}$ in RPMI 1640 medium containing $100 \mathrm{ng} / \mathrm{ml} \mathrm{NGF}$. PC12 cells stably overexpressing bcl-2 or an empty neomycin-resistant construct (lines bcl-2.1 and PC12neo.1, respectively) were generated and characterized as described previously (Batistatou et al., 1993).

Sympathetic neuron cultures were derived from sympathetic ganglia of 1- to 2-d-old rat pups (Troy et al., 1996; Stefanis et al., 1997). After trypsinization, the ganglia were plated on 24-well dishes at $0.5-1$ ganglia per dish in RPMI 1640 medium containing 10\% heat-inactivated horse serum and $100 \mathrm{ng} / \mathrm{ml}$ mouse NGF (Sigma, St. Louis, MO). One day after plating, uridine and 5-fluorodeoxyuridine (10 $\mu \mathrm{M}$ each) were added.

\section{Survival assays}

PC12 cells. Naive and neuronally differentiated PC12 cells were mechanically dissociated from $100 \mathrm{~mm}$ dishes after five rinses with serum-free RPMI 1640 medium and were washed with the same medium three to four times by centrifugation and resuspension. Cells were replated in collagen-coated 24-well or $35 \mathrm{~mm}$ dishes. At the indicated times, the numbers of viable cells were determined by quantifying the number of intact nuclei as described previously (Rukenstein et al., 1991). Counts were performed in triplicate and are reported as mean \pm SEM. We have shown previously that this method reliably assesses the number of viable cells (Rukenstein et al., 1991; Farinelli and Greene, 1996; Stefanis et al., 1997). In particular, we have found that cells counted as alive with this method, after caspase inhibitor or antisense caspase-2 application, are capable of responding to NGF (Troy et al., 1997; our unpublished observations).

In a limited set of experiments, nuclear staining of PC12 cells was performed with Hoechst $33342(1 \mu \mathrm{g} / \mathrm{ml}$; Sigma $)$ on poly- $D$-lysine-coated $35 \mathrm{~mm}$ dishes after fixation with paraformaldehyde as described previously (Farinelli and Greene, 1996).

Sympathetic neurons. At day 3 or 4 after plating, the sympathetic neuron cultures were washed three times with RPMI 1640 medium, followed by the addition of RPMI 1640 medium containing $10 \%$ horse serum and anti-mouse NGF (1:200; Sigma), with or without $100 \mu \mathrm{M}$ zVAD-FMK or DEVD-FMK. Alternatively, after the washes, RPMI 1640 medium with $10 \%$ horse serum and mouse NGF $(100 \mathrm{ng} / \mathrm{ml})$ was added. Survival was assessed by counting the number of phase-bright neuronal cells in a central strip of each well at $48 \mathrm{hr}$ after NGF deprivation and is reported relative to the number of neurons present at time 0 after NGF deprivation (Troy et al., 1996; Stefanis et al., 1997). Counts were performed in triplicate and are reported as mean \pm SEM.

\section{In vitro assay of caspase- 2 cleavage by ICE}

Caspase- 2 was cloned from PC12 cells by reverse transcription (RT)$\mathrm{PCR}$ in a TA cloning vector (Invitrogen, San Diego, CA). The sequence of this clone is identical to the rat Nedd-2 reported by Sato et al. (1997). A mutant construct with change of Asp to Asn for the site D333 was generated by PCR site-directed mutagenesis (Erlich, 1989). The presence of the mutation and the absence of other changes in the construct were verified by DNA sequencing. The wild-type and the mutant caspase- 2 construct were subcloned into a PET-16b vector (Novagen, Madison, WI) and used for the generation of radioactively labeled caspase- 2 protein via in vitro transcription-translation, using the Promega (Madison, WI) rabbit reticulocyte system. The wild-type or mutated caspase- 2 protein were incubated with $60 \mathrm{U}$ of ICE (caspase-1) for $2 \mathrm{hr}$ at $37^{\circ} \mathrm{C}$ in a buffer of $25 \mu \mathrm{M}$ HEPES, pH 7.5, 10\% sucrose, 0.1\% 3-[(3cholamidopropyl)dimethylammonio]-1-propanesulfonate (CHAPS), and $10 \mathrm{~mm}$ DTT and then resolved on SDS-polyacrylamide gels. The bands were subsequently visualized by fluorography.

\section{Preparation of cell lysates for Western blotting or assay of caspase activity}

Naive and neuronally differentiated PC12 cells were harvested at the indicated times after withdrawal of trophic support. Cells were rinsed in cold PBS and then collected in a buffer of $25 \mathrm{mM}$ HEPES, pH 7.5, $5 \mathrm{~mm}$ EDTA, 1 mm EGTA, 5 mm $\mathrm{MgCl}_{2}, 2$ mm DTT, $10 \mu \mathrm{g} / \mathrm{ml}$ each pepstatin and leupeptin, and $1 \mathrm{~mm}$ PMSF. The cellular material was left for $20 \mathrm{~min}$ on ice and then was sonicated on ice. The lysate was centrifuged for 20 min at $160,000 \times g$, and the supernatant was stored at $-80^{\circ} \mathrm{C}$ to be used for the DEVD-AFC-cleaving assay and for Western blotting with the anti-N-Nedd antibody (Miller et al., 1993; Stefanis et al., 1996, 1997). The pellet was used for poly-ADP-ribose polymerase (PARP) immunoblotting. In certain cases, supernatants of cell lysates that had not been deprived of trophic support were incubated with ICE for the indicated times at $37^{\circ} \mathrm{C}$ in a buffer of $25 \mathrm{~mm}$ HEPES, pH 7.5, $10 \%$ sucrose, $0.1 \%$ CHAPS, and $10 \mathrm{~mm}$ DTT, and then subjected to Western immunoblotting with the anti-N-Nedd antibody. The pellet was solubilized in $25 \mathrm{~mm}$ HEPES, pH 7.5, 5 mм EDTA, 2 mм DTT, $1 \%$ Triton X-100, $10 \mu \mathrm{g} / \mathrm{ml}$ each pepstatin and leupeptin, and $1 \mathrm{mM}$ PMSF, sonicated, and used for Western blotting with the PARP antibody. A signal corresponding to PARP was detected only in the pellet lysates and not in the supernatants. Protein concentrations were measured using the Bradford assay (Bradford, 1976).

\section{Western blotting}

Equal volumes of $2 \times$ sample buffer were added to cytoplasmic lysates of PC12 cells (100 $\mu \mathrm{g}$ of protein), and the samples were boiled for $5 \mathrm{~min}$, subsequently resolved by SDS-PAGE, transferred to nitrocellulose membranes, blocked in 5\% nonfat milk in PBS, and incubated overnight at $4^{\circ} \mathrm{C}$ with anti-N-Nedd, an antibody directed against the $\mathrm{N}$ terminus of caspase-2 (1:250) (Stefanis et al., 1997; Troy et al., 1997). Equal volumes of $2 \times$ sample buffer were added to lysates from PC12 pellets $(100 \mu \mathrm{g}$ of protein), and the samples were boiled for $5 \mathrm{~min}$, subsequently resolved on $10 \%$ SDS-polyacrylamide gels, and similarly subjected to immunoblotting using the C2-10 PARP monoclonal antibody [1:10000; Enzyme Systems Products (ESP), Dublin, CA]. The blots were washed in washing buffer (PBS with $0.2 \%$ Tween 20), incubated for $1 \mathrm{hr}$ at room temperature with anti-rabbit IgG antibody (for the Nedd-2 antibody) (Amersham, Arlington Heights, IL) or the anti-mouse IgG antibody (for the PARP antibody) (Amersham) at 1:1000 in blocking buffer, washed again in washing buffer, and then processed by ECL (Amersham) or with the Pierce (Rockford, IL) supersignal substrate system, according to the manufacturers' instructions. In certain cases, quantification of the bands was performed by scanning and analysis with the NIH Image software. Processing activity was defined as the ratio of processed product over processed product plus the remaining proform.

\section{Cleavage of fluorogenic substrate}

Lysates $\left(50 \mu \mathrm{g}\right.$ of protein) were incubated at $37^{\circ} \mathrm{C}$ in a buffer of $25 \mathrm{~mm}$ HEPES, pH 7.5, $10 \%$ sucrose, $0.1 \%$ CHAPS, and $10 \mathrm{~mm}$ DTT with the fluorogenic substrate DEVD-AFC (ESP), and the emitted fluorescence was measured in a fluorometer as described previously (Nicholson et al., 1995; Stefanis et al., 1996).

\section{Reagents}

zVAD-FMK, BAF, and DEVD-FMK (fluoromethylketone) were obtained from ESP; YVAD-CMK was obtained from Bachem (King of Prussia, PA); aurintricarboxylic acid (ATA), actinomycin- $D$, and $\mathrm{N}$-acetylcysteine (NAC) were obtained from Sigma; and 8-(4chlorophenylthio)-cAMP (CPT c-AMP) was obtained from Boehringer Mannheim (Indianapolis, IN). Flavopiridol was a generous gift from Dr. Peter Worland (National Institutes of Health). Human recombinant NGF was kindly provided by Genentech (San Francisco, CA). The antisense to caspase-2 was generated and coupled to penetratin 1 as described previously (Troy et al., 1996, 1997). Purified recombinant human ICE was kindly provided by N. A. Thornberry (Merck Laboratories).

\section{RESULTS}

\section{Caspase-2 processing in PC12 cells correlates temporally with the induction of caspase-3-like activity after withdrawal of trophic support}

PC12 cells, after withdrawal of serum, undergo apoptotic death that begins to be apparent by $4-5 \mathrm{hr}$ after deprivation. By $24 \mathrm{hr}$, 
A

\section{hrs after serum deprivation}

\section{$\begin{array}{lllll}0 & 2 & 3 & 5 & 5 \mathrm{~N}\end{array}$}

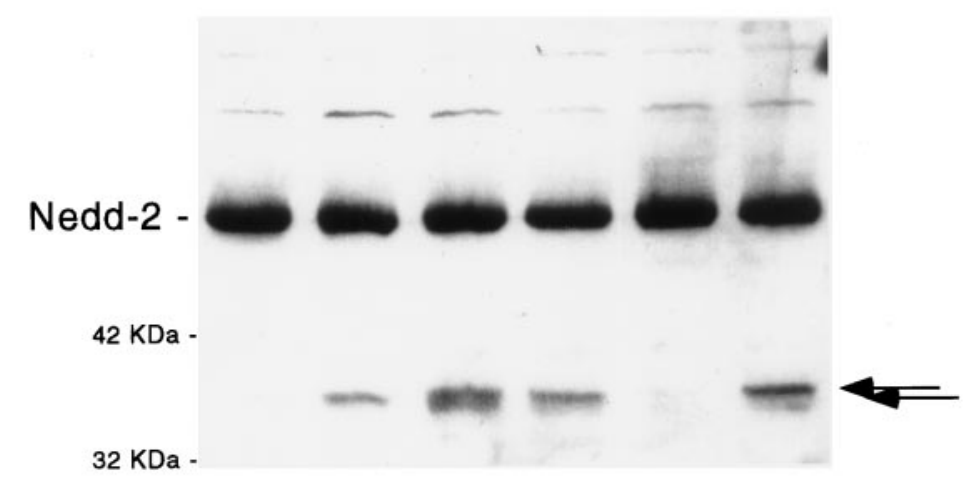

B

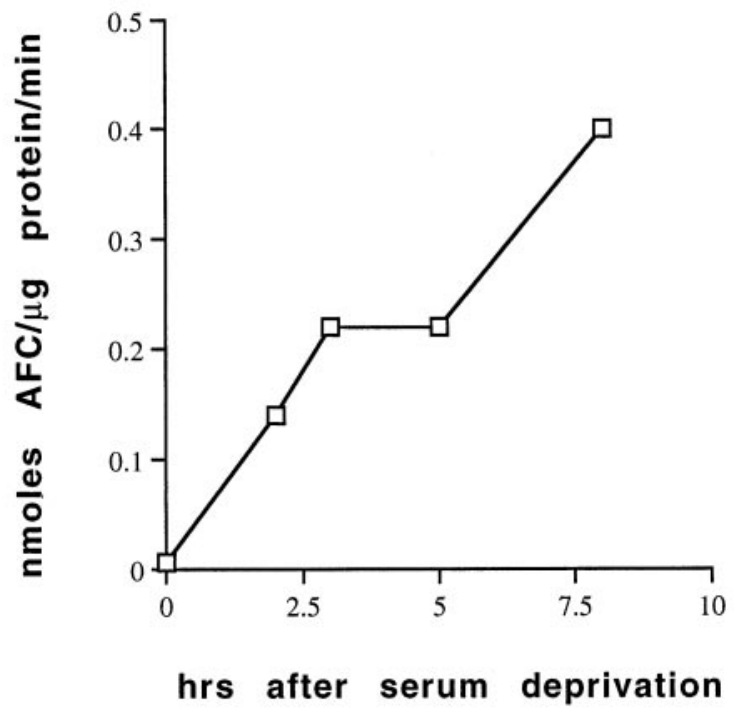

C

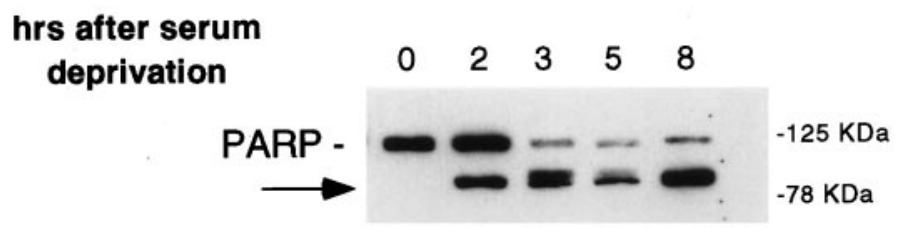

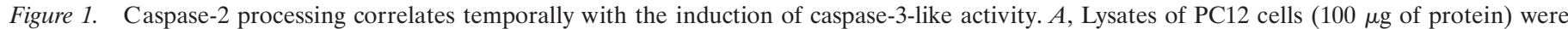

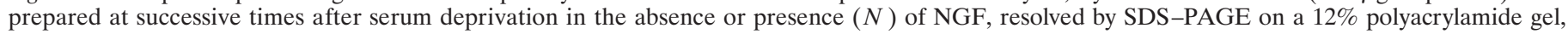

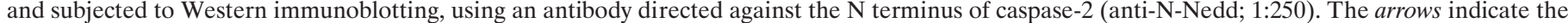

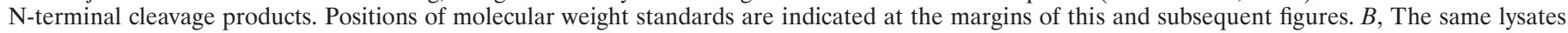

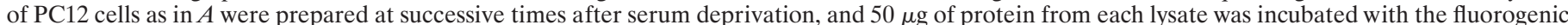

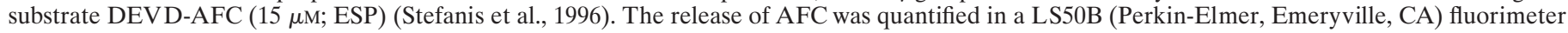

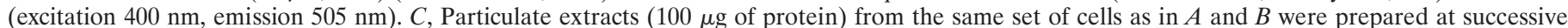

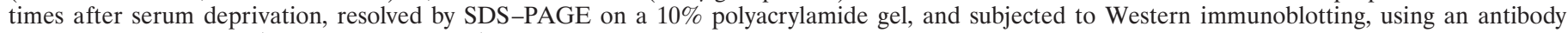
directed against PARP (C2-10; 1:10000; ESP). The arrow indicates the cleavage product of PARP.

$>75 \%$ of the cells are dead (Greene, 1978; Rukenstein et al., 1991; Stefanis et al., 1996). To examine the processing of caspase-2 evoked by withdrawal of trophic support from PC12 cells, we prepared extracts of these cells at successive times after serum deprivation and subjected them to Western immunoblotting using an antibody directed against the $\mathrm{N}$ terminus of caspase-2 (Stefanis et al., 1997; Troy et al., 1997). Caspase-2 (approximate molecular weight of $51 \mathrm{kDa}$ ) began to be processed to a $37 \mathrm{kDa} \mathrm{N}$-terminal fragment within $2 \mathrm{hr}$ after serum deprivation in PC12 cells, at a time when there is no cell death discernible in the cultures. A faint cleavage product of $\sim 36 \mathrm{kDa}$ was also appreciated on certain blots. Treatment of serumdeprived cells with NGF prevented formation of the cleavage products (Fig. 1A).

Processing of caspase- 2 and caspase-3-like activity in the same cell has been reported previously (Harvey et al., 1997; Li et al., 1997). Harvey et al. (1997) reported that caspase-2 processing preceded caspase- 3 processing. ICE-like (caspase-1) activity appears to precede caspase-3-like activity (Enari et al., 1996; Harvey et al., 1998) and to occur upstream of bcl-2 (Harvey et al., 1998).
These data have led to the idea that caspases with long prodomains, such as caspase-1 and caspase-2, may act upstream of death effector caspases, such as caspase-3, that lack such prodomains (Harvey et al., 1997, 1998). To investigate the temporal relationship between caspase- 2 processing and caspase-3-like activity in our system, we used the same lysates that demonstrated caspase-2 processing to detect cleavage of the fluorogenic caspase-3 substrate DEVD-AFC. DEVD represents the cleavage site on human PARP, which is the prototypical substrate for caspase-3 (Nicholson et al., 1995). As we have reported previously, caspase-3-like activity was induced within $2 \mathrm{hr}$ of serum deprivation (Stefanis et al., 1996). The time course of the induction of this activity correlated with that of caspase- 2 processing (Fig. $1 B$ ). As another measure of endogenous caspase-3-like activity, we used particulate fractions of PC12 cell lysates at successive times after serum deprivation and subjected them to immunoblotting, using a monoclonal antibody against PARP. As shown in Figure $1 C$, we found that this measure of caspase-3-like activity also correlated temporally with caspase- 2 processing.

These results indicate that the induction of caspase- 2 process- 
A

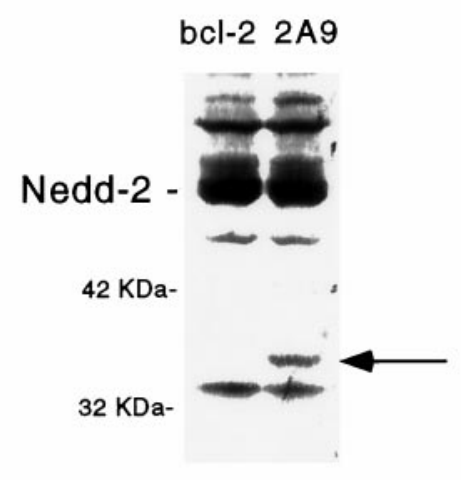

B

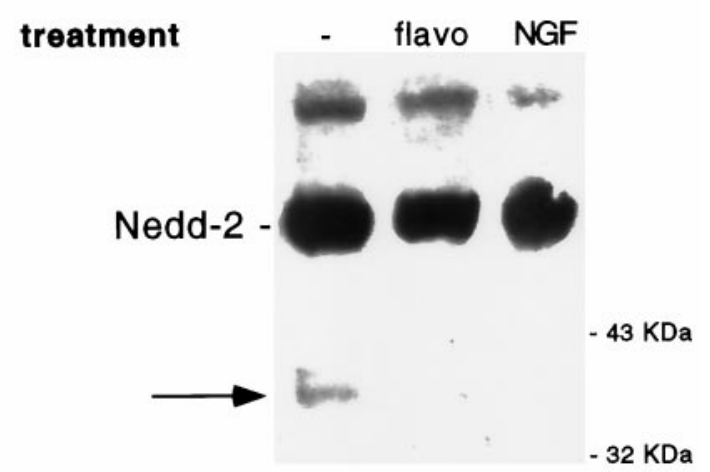

Figure 2. A variety of survival-promoting agents act upstream of caspase-2 processing. $A$, PC12 cells permanently transfected with an empty vector (2A9) or with human bcl-2 were subjected to withdrawal of trophic support and $6 \mathrm{hr}$ later were harvested for assessment of caspase-2 processing, using the N-terminal antibody. The arrow denotes the cleavage product that was present in the 2A9, but not the bcl-2, cells. The asterisk indicates a nonspecific band, which was more prominent in this case because the nonpurified antiserum was used in this experiment. $B$, Neuronally differentiated PC12 cells

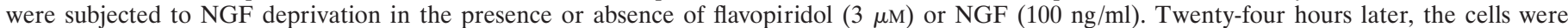
harvested for assessment of caspase-2 processing, using immunoblotting with anti-N-Nedd. The arrow denotes the N-terminal cleavage fragment that is present only in the untreated cells.

ing and caspase 3-like activity occur at approximately the same temporal point in the apoptotic pathway.

\section{Caspase-2 processing is abrogated by a number of agents that promote survival}

We have identified previously a number of agents that promote survival after withdrawal of trophic support from PC12 cells. To determine the point in the apoptotic pathway at which these agents intervene, we have tested them previously for their abilities to inhibit the induction of jun kinase and caspase-3-like activities that occur in this model of cell death (Park et al., 1996b; Stefanis et al., 1996). Because caspase-2 processing appears to be a critical step in the apoptotic pathway in this model (Stefanis et al., 1997; Troy et al., 1997), we assessed whether these agents would also prevent the induction of caspase- 2 processing and therefore act upstream of this event.

Lysates of PC12 cells transfected with the anti-apoptotic molecule bcl-2 (Batistatou et al., 1993) did not show processing of caspase-2 in response to serum deprivation, whereas lysates of cells transfected with an empty vector demonstrated processing 5 hr after serum deprivation (Fig. $2 A$ ). Lysates of PC12 cells treated at the time of withdrawal of trophic support with the survival-promoting agents cAMP (Rydel and Greene, 1988; Rukenstein et al., 1991), ATA (Batistatou and Greene, 1991), and NAC (Ferrari et al., 1995) also showed little N-terminal processing of caspase-2 (data not shown).

We have shown previously that neuronally differentiated PC12 cells also undergo processing of caspase-2 as early as $10 \mathrm{hr}$ after NGF deprivation (Stefanis et al., 1997). At this time point, there is no discernible cell death in the cultures. The $37 \mathrm{kDa}$ product of caspase- 2 processing in neuronally differentiated PC12 cells is less apparent than in naive cells, presumably because of the less synchronous death of the cells in the former paradigm. Cdk inhibitors, which inhibit the cell cycle, abrogate cell death induced by NGF deprivation in neuronally differentiated PC12 cells and sympathetic neurons (Park et al., 1996a). We tested whether one such inhibitor, flavopiridol, would abrogate the induction of caspase- 2 processing in neuronally differentiated PC12 cells. Application of flavopiridol at the time of NGF deprivation prevented the N-terminal processing of caspase-2 (Fig. $2 B$ ). Similar results, with inhibition of $\mathrm{N}$-terminal caspase-2 processing, were achieved with the inhibitor of transcription actinomycin- $D$, which has been shown also to promote survival of neuronally differentiated PC12 cells (data not shown) (Mesner et al., 1992).

In summary, as in the case of induction of caspase-3-like activity, all the survival agents tested appear to inhibit caspase-2 processing. This would place caspase- 2 processing and caspase3-like activation at a point downstream of the site of action of these agents.

\section{Identification of a potential caspase-2 cleavage site in PC12 cells}

Present findings indicate that cleavage (and consequent activation) of caspases is generally performed by members of the caspase family and/or by granzyme B and that such proteolysis occurs at specific aspartate residues (Thornberry et al., 1992; Xue et al., 1996). However, recent data indicate that noncanonical proteolysis at nonaspartate residues by serine proteases may also lead to the activation of caspases (Zhou and Salvesen, 1997). We wished therefore to determine whether the observed $37 \mathrm{kDa}$ $\mathrm{N}$-terminal cleavage of caspase- 2 in $\mathrm{PC} 12$ cells could be performed by a caspase. To this end, we incubated lysates of healthy PC12 cells with the prototypical caspase ICE (caspase-1). The products were then subjected to Western blot analysis with the Nedd-2 antiserum. This revealed time-dependent processing of caspase-2 to a $37 \mathrm{kDa}$ fragment that comigrated with one generated when the cells were deprived of trophic support (Fig. 3A). Thus, ICE appears to cleave caspase- 2 at the same site as the endogenous protease(s). It should be stressed that this in vitro assay was used only to demonstrate that the processed fragment observed within cells corresponds to a fragment generated by a member of the caspase family and is not meant to demonstrate that ICE itself is involved in this processing within cells. Indeed, previous results (Stefanis et al., 1996; Troy et al., 1996) and current data (see below) indicate that ICE is not involved in such processing or in cell death in this model.

The site equivalent to D333 in rat caspase-2 has been identified previously as an autocleavage site on human (Xue et al., 1996) 


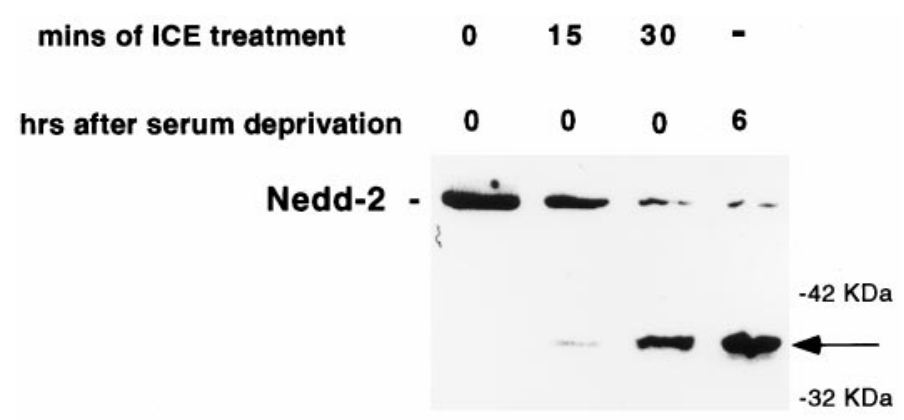

Figure 3. The $37 \mathrm{kDa}$ cleavage product of caspase-2 generated within PC12 cells after serum deprivation corresponds to a caspase cleavage site at an aspartate residue. Lysates of PC12 cells prepared without serum deprivation were incubated with $60 \mathrm{U}$ of ICE in a buffer containing $25 \mathrm{~mm}$ HEPES, pH 7.5, $10 \%$ sucrose, $0.1 \%$ CHAPS, and $10 \mathrm{~mm}$ DTT for the indicated times. The samples were subjected to Western immunoblotting using anti-N-Nedd at 1:250. In the last lane, a lysate of PC12 cells prepared at $6 \mathrm{hr}$ after serum deprivation was similarly subjected to Western immunoblotting on the same blot. The arrow indicates the N-terminal cleavage product.

and mouse (Allet et al., 1996) caspase-2, which would produce an $\mathrm{N}$-terminal product of $\sim 37 \mathrm{kDa}$. To verify that ICE cleaves rat caspase-2 at this site, we developed an in vitro assay for cleavage of radiolabeled caspase-2 (produced by in vitro transcriptiontranslation) by ICE. We used site-directed mutagenesis to generate a form of caspase-2 that was mutated at the D333 site (Asp to Asn). This mutant form showed lack of processing by ICE to 37 and $14 \mathrm{kDa}$ fragments compared with the wild-type caspase-2 (data not shown).

Together, these findings are consistent with the model that intact caspase- 2 is processed at an aspartate residue by caspases in trophic factor-deprived PC12 cells and that the $37 \mathrm{kDa}$ N-terminal fragment reflects cleavage at D333.

\section{Caspase-3-like activity is not required for $\mathbf{N}$-terminal processing of caspase-2}

Our results with the in vitro cleavage assays indicate that a caspase(s) could be involved in the N-terminal caspase- 2 processing. We first turned our attention to the caspase-3-like subfamily of caspases and to the possibility that they may be involved in this processing. As shown above, withdrawal of trophic support from PC12 cells induces a caspase-3-like activity that correlates temporally with the onset of caspase- 2 processing. Moreover, caspase- 3 has been reported to have a special affinity for substrates with the motif DXXD (Casciola-Rosen et al., 1996). This motif (DQQD) is present at the cleavage site discussed above (amino acids 330-333 on Nedd-2), and caspase-3 has been shown to process Ich-1, the human homolog of caspase-2, in vitro (Xue et al., 1996). To investigate whether a caspase-3-like activity could be responsible for the processing and activation of caspase-2, we used various concentrations of the caspase inhibitor DEVDFMK, which is relatively selective for DEVD-cleaving caspase3-like caspases (Nicholson et al., 1995). This inhibitor was administered to PC12 cells at the time of serum deprivation, and cell lysates were prepared $6 \mathrm{hr}$ later and evaluated in parallel for caspase-3-like activity and caspase-2 cleavage. Caspase-3-like activity was measured by cleavage of the fluorogenic substrate DEVD-AFC by cell lysates and by cleavage of the endogenous PARP present in PC12 cells. To ensure that unbound DEVDFMK was not present during the DEVD-AFC-cleavage assays, we mixed untreated samples with samples treated with DEVD-
FMK and found that there was no inhibition of activity (data not shown).

As shown in Figure $4 A$, N-terminal caspase-2 processing was essentially unaffected by concentrations of DEVD-FMK up to $100 \mu \mathrm{M}$. In contrast, $1 \mu \mathrm{M}$ DEVD-FMK was sufficient to cause a significant reduction of caspase-3-like activity. DEVD-AFCcleaving activity was essentially eliminated in cells exposed to 10 $\mu \mathrm{M}$ DEVD-FMK. At this concentration of DEV D-FMK, PARPcleaving activity plateaued at a level $\sim 50 \%$ of the activity in untreated controls (Fig. $4 A$ ). Pretreatment with DEVD-FMK (50 $\mu \mathrm{M})$ for $4 \mathrm{hr}$ before withdrawal of serum or assessment at later times did not alter this plateau (Fig. $4 B$ ) and did not alter the lack of effect on caspase-2 processing, as shown in Figure $4 C$. These findings thus rule out caspase- 3 or other caspase-3-like caspases as the major activators of caspase-2 in our system.

\section{Role of noncaspase-3-like caspases in caspase-2 processing and PARP cleavage}

The idea that a caspase(s) other than a caspase-3-like caspase is responsible for the processing of caspase- 2 was tested using the more general caspase inhibitors zVAD-FMK and BAF. At a concentration of $100 \mu \mathrm{M}$, a concentration at which DEVD-FMK was ineffective, both inhibitors inhibited caspase-2 processing (Fig. 4D). In contrast, YVAD-CMK, an inhibitor relatively selective for ICE, did not appreciably affect caspase-2 processing, even at $250 \mu \mathrm{M}$ (data not shown). This is consistent with the absence of induction of ICE-like activity and the lack of a survival-promoting effect of YVAD-CMK in this model of cell death, as we have reported previously (Stefanis et al., 1996; Troy et al., 1996).

The absence of DEVD-cleaving activity (measured by the fluorogenic substrate) and the plateau of PARP-cleaving activity at concentrations of DEVD-FMK higher than $10 \mu \mathrm{M}$ indicate that proteases other than caspase-3-like caspases may be partly responsible for PARP processing in trophic factor-deprived PC12 cells. These proteases are likely to be caspases, because zVADFMK and BAF at concentrations of $100 \mu \mathrm{M}$ completely abrogate PARP cleavage in this paradigm (Fig. $4 B$ ).

In summary, it appears that DEVD-FMK affects caspase-3-like activity at concentrations at least two orders of magnitude lower than required to begin to affect caspase- 2 processing. It is therefore highly unlikely that caspase-3-like proteases are involved in caspase- 2 processing. In contrast, one or more caspases that do not belong to the caspase-3-like or the caspase-1-like subfamily appear to be involved in caspase- 2 processing to the $37 \mathrm{kDa}$ product.

\section{Caspase 3-like activity is not required for PC12 and sympathetic neuron cell death caused by trophic factor deprivation}

Survival of PC12 cells at various concentrations of DEVD-FMK was assessed in parallel with caspase-2 processing and caspase-3like activity. A concentration of $10 \mu \mathrm{M}$ DEVD-FMK, which inhibited caspase-3-like activity almost completely, had only small effects on survival (Fig. 4A). With $25 \mu \mathrm{M}$ DEVD-FMK, which abolished detectable caspase-3-like activity (as assessed by DEVD-AFC cleavage) completely, $76 \%$ of the cells still died (Fig. 4A). To examine the possibility that these cells were undergoing a nonapoptotic form of cell death in the absence of caspase3-like activity, we stained serum-deprived PC12 cells treated with 10 or $25 \mu \mathrm{M}$ DEVD-FMK with the nuclear dye Hoechst 33342 (1 $\mu \mathrm{g} / \mathrm{ml}$; Sigma). We found that the classic morphological hallmarks of apoptosis, such as nuclear condensation and chromatin 


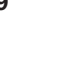

A

PARP-cleaving

DEVD-cleaving

relative survival

100

75

33

33

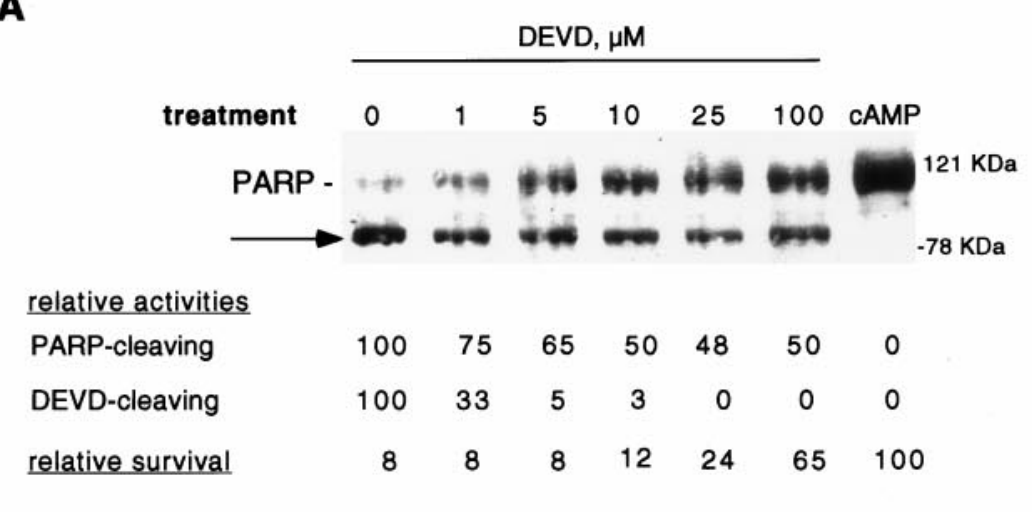

relative activities

88

DEVD, $\mu \mathrm{M}$

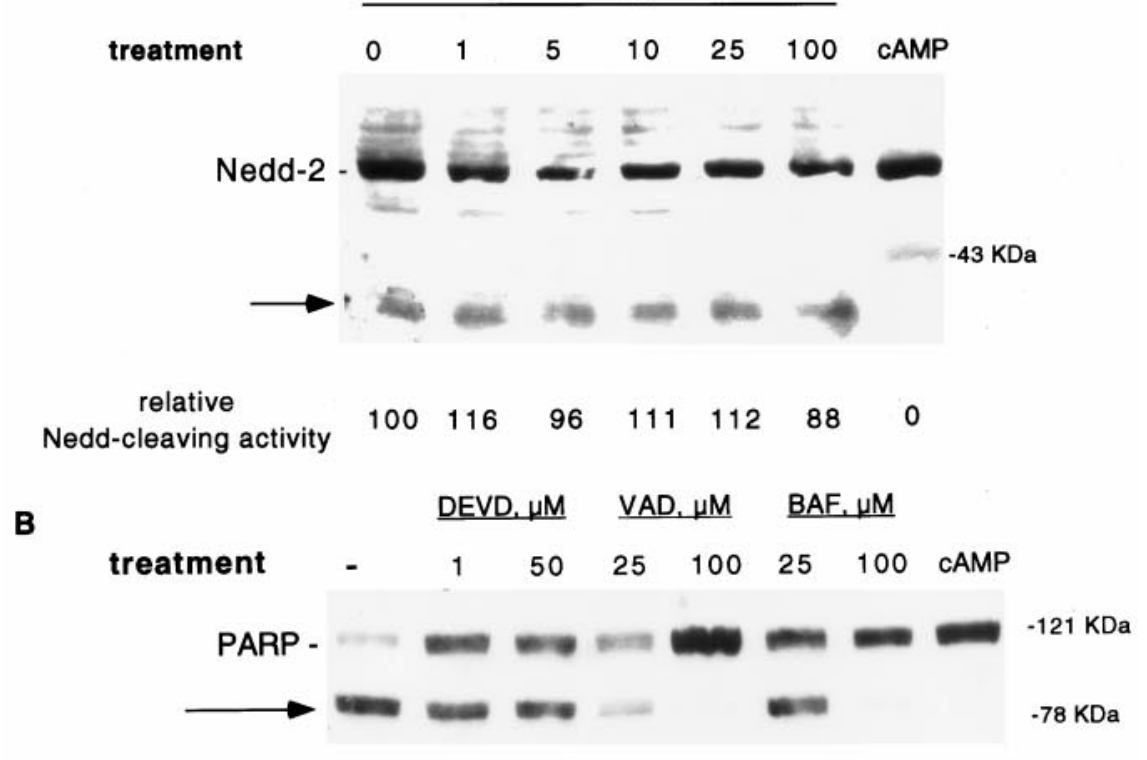

C

treatment $\quad$ cAMP - DEVD-FMK

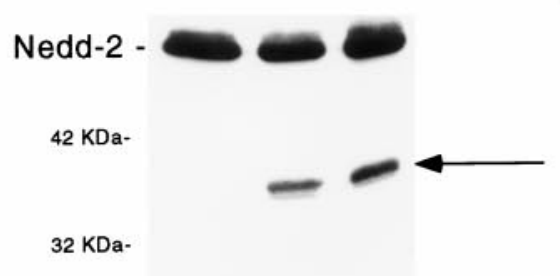

D

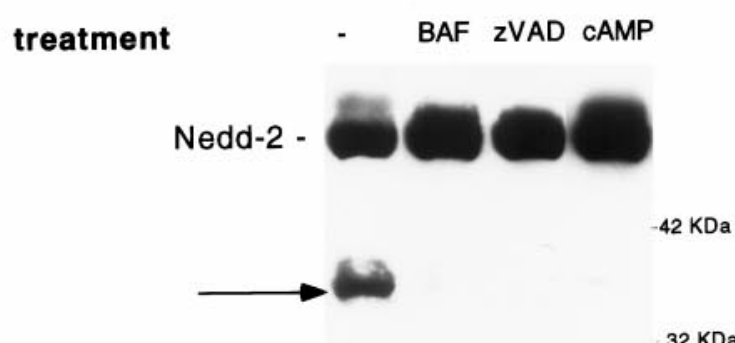

Figure 4. Caspase-2 is processed by a noncaspase3 -like caspase. $A, \mathrm{PC} 12$ cells were deprived of serum in the presence or absence of various concentrations of DEVD-FMK or $100 \mu \mathrm{M}$ CPT-cAMP. Six hours later, the cells were harvested for assessment of PARP cleavage (top panel), using immunoblotting with the C2-10 antibody (1:10000), and for caspase-2 cleavage (bottom panel), using immunoblotting with anti-N-Nedd (1:250). The arrows denote the cleavage products of PARP and caspase-2. Lysates of these cells were also used for measurement of DEVD-AFC cleavage activity, as described in Materials and Methods. The activities are reported relative to those of untreated controls. Replicate cultures from the same set of cells were used for assessment of survival $(n=3)$. B, PC12 cells were deprived of serum in the presence or absence of CPT-cAMP $(100 \mu \mathrm{M})$ or the indicated concentrations of DEVD-FMK, zVAD-FMK, or BAF. For all three caspase inhibitors, a $4 \mathrm{hr}$ pretreatment was also applied to the cells. Twelve hours after serum deprivation, lysates were harvested for the assessment of PARP processing, using immunoblotting with the C2-10 antibody (1:10000). The arrow denotes the cleavage product of PARP. $C, \mathrm{PC} 12$ cells were deprived of serum in the presence or absence of CPTcAMP $(100 \mu \mathrm{M})$ or DEVD-FMK $(50 \mu \mathrm{M}$, with pretreatment for $4 \mathrm{hr}$ ). Twelve hours later, lysates were harvested for assessment of caspase- 2 processing, using immunoblotting with anti-N-Nedd (1:200). The arrow denotes the cleavage product of $37 \mathrm{kDa}$. $D$, PC12 cells were deprived of serum in the presence or absence of $100 \mu \mathrm{M}$ zVAD-FMK, BAF, or CPT-cAMP. Six hours later, the cells were harvested for assessment of caspase-2 cleavage, using immunoblotting with anti-N-Nedd. The arrow denotes the $\mathrm{N}$-terminal cleavage product. 
clumping and margination, were still apparent in dying cells treated with 10 or $25 \mu \mathrm{M}$ DEVD-FMK (Fig. $5 A$ ). Therefore, apoptotic cell death was still ongoing in the absence of caspase3-like activity.

We extended these observations to neuronally differentiated PC12 cells cultured in the absence of NGF, because these cells serve as a model for the death of sympathetic neurons after NGF deprivation. As in the naive PC12 cells, caspase-3-like activity was completely dissociated from cell death when neuronally differentiated PC12 cells were deprived of NGF in the presence of various concentrations of DEVD-FMK (Fig. $5 B$ ). At a concentration of $100 \mu \mathrm{M}$ DEVD-FMK, there were minimal effects on survival, although caspase-3-like activity was undetectable.

We next assessed the effect of $100 \mu \mathrm{M}$ DEVD-FMK on survival of sympathetic neurons deprived of NGF for $48 \mathrm{hr}$. At this concentration, which abolishes caspase-3-like activity in naive and neuronally differentiated PC12 cells, as well as in cultured embryonic cortical neurons (L. Stefanis, W. J. Friedman, L. A. Greene, D. S. Park, unpublished results), there was only a minor effect on survival (Fig. 5C). In contrast, and as we have previously reported (Troy et al., 1996), the more general caspase inhibitor zVAD-FMK at the same concentration offered protection similar to the one achieved with NGF.

Together, these findings indicate that caspase-3-like activity does not play a required role in the apoptotic death of PC12 cells or sympathetic neurons triggered by loss of trophic support.

\section{Downregulation of caspase-2 has no effect on caspase-3-like activity}

We have shown previously that downregulation of caspase- 2 by $60-70 \%$ with the use of an Antannepedia-coupled caspase-2 antisense construct enhances survival of PC12 cells and sympathetic neurons after withdrawal of trophic support. A scrambled oligonucleotide with the same nucleotide composition had no effect on survival (Troy et al., 1997). To further investigate the relationship between caspase-2 and caspase-3-like activation in this paradigm, we tested lysates of serum and NGF-deprived PC12 cells, untreated or treated with antisense caspase-2, for their ability to cleave the fluorogenic substrate DEVD-AFC. As shown in Figure 6, $A$ (serum-deprived) and $C$ (neuronally differentiated and NGF-deprived cells), lysates from the antisense caspase-2-treated cultures possessed caspase-3-like activity similar to untreated controls. Experiments from the same sets of cells done in parallel confirmed that antisense caspase- 2 provided protection from withdrawal of trophic support for both naive and differentiated PC12 cells (Fig. 6B,D). These results indicate that depletion of caspase-2 to a level that prevents death does not affect caspase-3-like activity. This suggests that caspase-2 is not required, directly or indirectly, for the induction of caspase-3-like activity in this paradigm. Furthermore, such findings indicate that activation of caspase- 3 is not sufficient to induce death in this system.

\section{DISCUSSION}

We have shown previously that caspase- 2 is processed to a $37 \mathrm{kDa}$ $\mathrm{N}$-terminal product after withdrawal of trophic support from PC12 cells (Stefanis et al., 1997; Troy et al., 1997) and that a caspase-3-like activity is induced in the same model (Stefanis et al., 1996). Our interest in caspase- 2 processing stems from our finding that this caspase is necessary for cell death in this experimental paradigm (Troy et al., 1997). In the current paper, we sought to identify upstream regulators of caspase-2 processing, which presumably ultimately lead to its activation, focusing especially on the relationship between caspase- 2 and caspase-3-like activity, and to investigate further the role of this caspase-3-like activity in this cell death model.

\section{Placing caspase-2 and caspase-3-like activity within the apoptotic pathway}

We found that caspase-2 processing, which leads to an intermediate N-terminal cleavage product of $37 \mathrm{kDa}$, correlated temporally with the induction of caspase-3-like activity. To further examine this correlation, we tested various agents that inhibit caspase-3-like activation for their ability to inhibit caspase-2 processing. These agents, including the anti-apoptotic protein bcl-2 and, in neuronally differentiated PC12 cells, the Cdk inhibitor flavopiridol, prevent the induction of caspase-2 processing as well, acting at some point further upstream. The inhibition of caspase- 2 processing by flavopiridol in particular, adds further weight to the idea that aberrant activation of components of the cell cycle is a necessary step in the apoptotic pathway and occurs upstream of caspase activation (Park et al., 1996a; Stefanis et al., 1996). This appears to be in contrast to lymphocyte cell death, in which $\mathrm{Cdk}$ activation occurs downstream of caspase activity (Harvey et al., 1998). Our results place caspase-2 processing and caspase-3-like activity at approximately the same temporal point in the PC12 cell apoptotic pathway. However, they do not address the issue of the relationship between these two activities. Three possibilities exist: (1) caspase-3-like activity is involved in caspase-2 processing, acting at some point further upstream in the apoptotic pathway; (2) caspase-2 is involved, directly or indirectly, in the generation of caspase-3-like activity; and (3) caspase- 2 processing and activation and caspase-3-like activity occur independently of each other, on parallel arms of the apoptotic pathway.

The first possibility could be supported by a number of circumstantial data (Casciola-Rosen et al., 1996; Xue et al., 1996). Li et al. (1997) have shown that with increasing concentrations of the caspase inhibitor DEVD-CHO there was similar inhibition of the caspase-3-like (PARP-cleaving) and caspase-2-cleaving activities that are induced in Jurkat cells after treatment with Fas ligand. They deduced that caspase- 2 was being processed by a caspase3-like molecule. The possibility therefore arose that a caspase-3like activity may be responsible for the processing of caspase- 2 in our experimental paradigm. We observed, however, using the caspase inhibitor DEVD-FMK, that we could inhibit all detectable caspase-3-like activity without affecting caspase-2 processing. It should be noted here that DEVD-based inhibitors may not be entirely selective for caspase-3-like caspases, as originally thought, but may still preferentially affect caspase-3 and caspase3-like caspases (Margolin et al., 1997). Caspase-3-like proteases therefore do not appear to be responsible for caspase-2 processing within PC12 cells after withdrawal of trophic support. These results contrast with the ones reported by Li et al. (1997) in Fas-treated Jurkat cells and may reflect differences either in the cellular systems and/or death stimuli used or in experimental design. If the former is true, this may be an example of the distinct manner in which members of the caspase family may interact depending on the system studied.

To examine the second possibility, we selectively inhibited caspase- 2 via the use of antisense technology. The antisense 
A

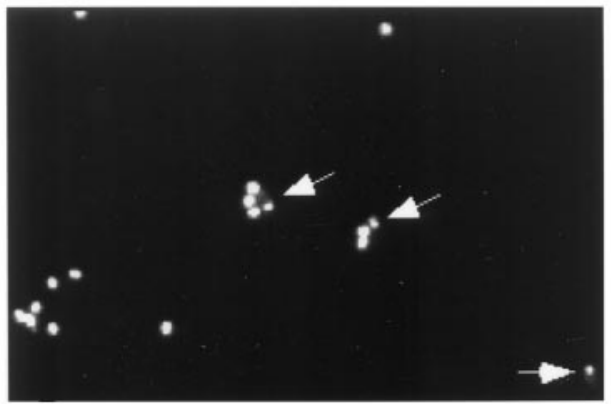

No additives

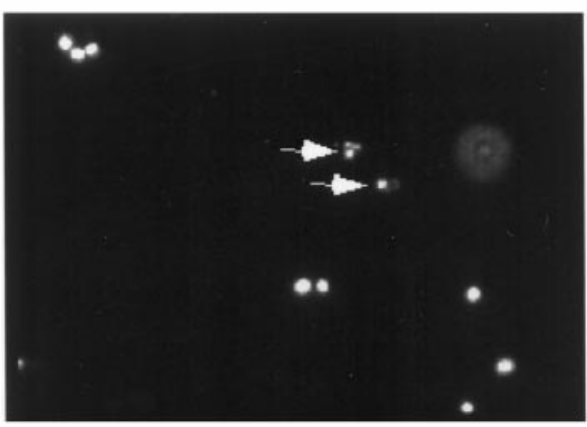

$10 \mu \mathrm{M}$ DEVD-FMK

B

$\frac{2}{ \pm}$

ס

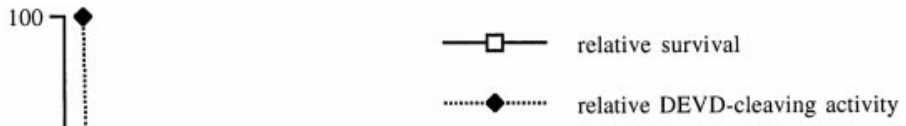

MM DEVD-FMK

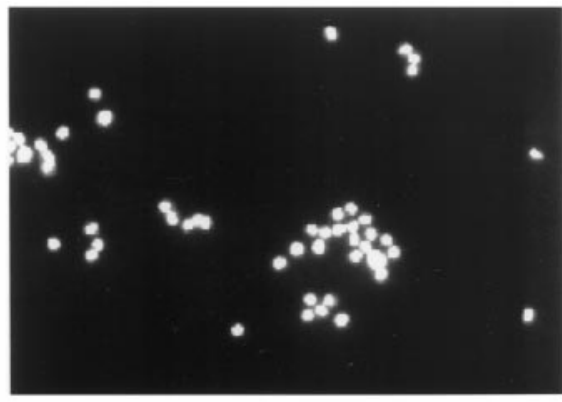

$50 \mu M$ zVAD-FMK

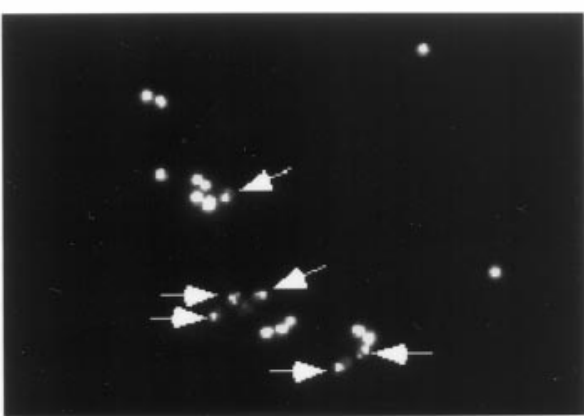

$25 \mu \mathrm{M}$ DEVD-FMK

C

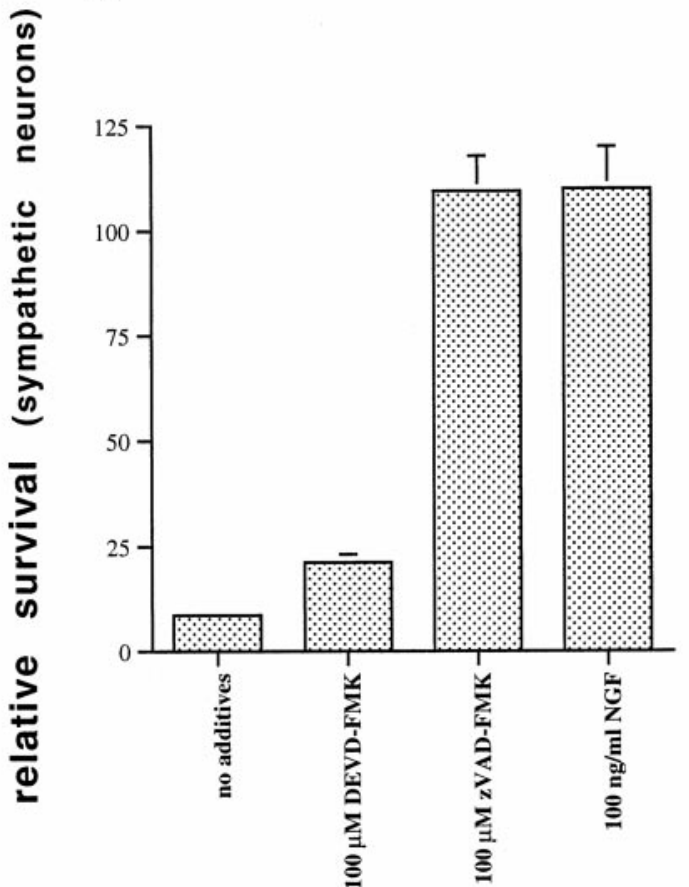

Figure 5. Apoptotic cell death occurs in the absence of caspase-3-like activity in PC12 cells and sympathetic neurons. $A$, PC12 cells were deprived of serum overnight in the presence or absence of the indicated concentrations of DEVD-FMK or zVAD-FMK. They were subsequently fixed and stained with Hoechst $33342(1 \mu \mathrm{g} / \mathrm{ml}$; Sigma). The arrows indicate apoptotic nuclei. $B$, Neuronally differentiated PC12 cells were deprived of NGF in the presence or absence of various concentrations of DEVD-FMK and assessed in parallel at $24 \mathrm{hr}$ for caspase-3-like activity and survival. Survival is reported as the number of intact nuclei present at $24 \mathrm{hr}$ relative to the number of nuclei present at time 0 after NGF deprivation and is given as mean \pm SEM of three samples. $C$, Cultured rat sympathetic neurons were deprived of NGF in the presence or absence of zVAD-FMK (100 $\mu \mathrm{M})$ or DEVD-FMK (100 $\mu \mathrm{M})$, and survival was assessed $48 \mathrm{hr}$ later. Sympathetic neurons treated with $100 \mathrm{ng} / \mathrm{ml} \mathrm{NGF}$ were assessed in parallel. Survival is reported relative to that in the same cultures before NGF deprivation and is given as mean \pm SEM of three samples. 

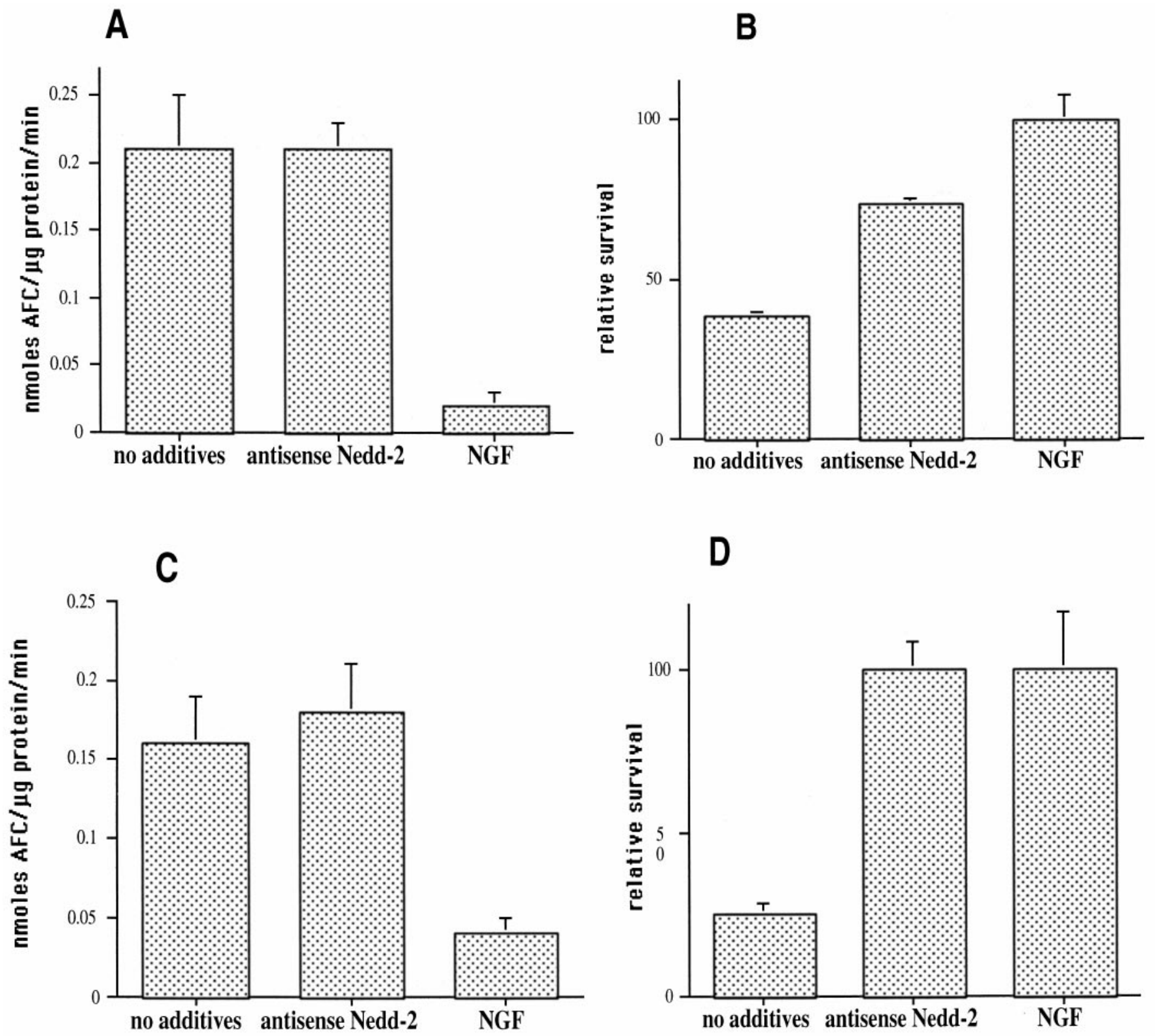

Figure 6. Downregulation of caspase-2 does not affect caspase-3-like activity. A, PC12 cells were deprived of serum in the presence or absence of antisense Nedd-2 (400 nM) or $100 \mathrm{ng} / \mathrm{ml}$ NGF. At $6 \mathrm{hr}$ after serum deprivation, cell lysates were assayed for the presence of DEVD-cleaving activity, as described in Materials and Methods. Results are expressed as mean \pm SEM of three samples. $B$, Replicate cultures from the same set of cells as in $A$ were assessed for survival at $24 \mathrm{hr}$ after NGF deprivation by counting the number of intact nuclei, as described in Materials and Methods. Results are expressed as mean \pm SEM of three samples. $C$, Neuronally differentiated PC12 cells were deprived of NGF in the presence or absence of antisense Nedd-2 (400 nM) or $100 \mathrm{ng} / \mathrm{ml}$ NGF. At $24 \mathrm{hr}$ after NGF deprivation, cell lysates were generated and tested for DEVD-cleaving activity, as described in Materials and Methods. Results are expressed as mean \pm SEM of three samples. $D$, Replicate cultures from the same set of cells as in $C$ were assessed for survival at $48 \mathrm{hr}$ after NGF deprivation by counting the number of intact nuclei, as described in Materials and Methods. Results are expressed as mean \pm SEM of three samples.

construct that we used has shown significant reduction of caspase-2 protein levels, whereas there was no downregulation of caspase-3 (Troy et al., 1997). Although the antisense oligonucleotide promoted survival, it had no effect on caspase-3-like activity. These results indicate that caspase- 2 does not lie upstream of caspase-3-like activity and does not contribute significantly to its generation. This would be in agreement with the observation that purified caspase-2 failed to cleave a DEVD-based fluorogenic substrate (Talanian et al., 1997). Therefore, this second possibility is also discarded.
The prevailing notion is that the multiple caspases that are present in a single cell are activated in a cascade (Enari et al., 1996; Fraser and Evan, 1996; Srinivasula et al., 1996). Because in our paradigm caspase-3-like activity does not appear to be upstream or downstream of caspase-2, by default we are left with the third possibility, with a model in which caspase-2 and caspase-3like activity lie in parallel arms of the apoptotic response. This lends support to the idea that parallel processing of caspases may occur at least in certain cases in response to apoptotic stimuli (Fig. 7). 


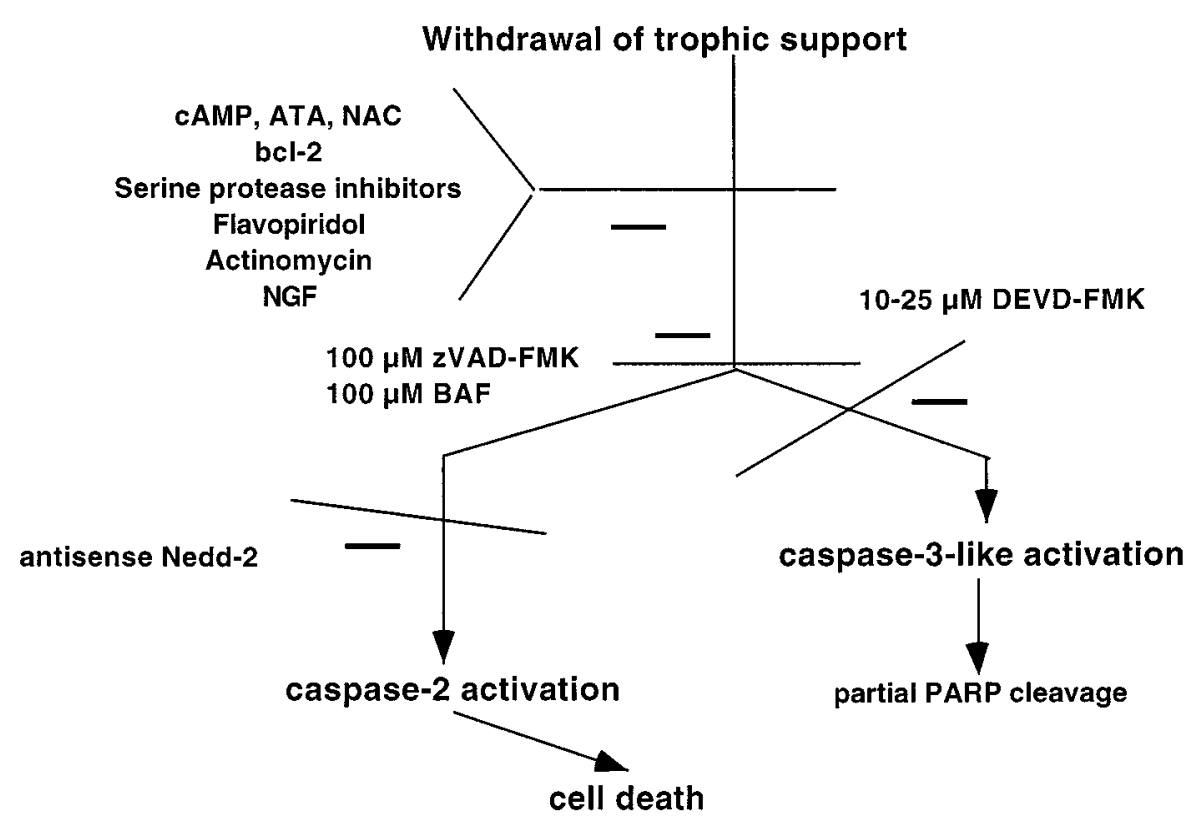

Figure 7. Model of activation of Nedd-2 (caspase-2) and CPP32-like (caspase-3) activity in apoptosis after withdrawal of trophic support from PC12 cells

\section{Potential upstream regulators of caspase-2 processing}

What then may process caspase- 2 within $\mathrm{PC} 12$ cells after trophic deprivation? Our results showing complete inhibition of caspase-2 processing with the general caspase inhibitors zVADFMK or BAF $(100 \mu \mathrm{M})$ would indicate that caspases are involved in this processing. In addition, the $37 \mathrm{kDa}$ band is likely to be generated by cleavage at an aspartate residue at the site D333. Such cleavage can be performed only by caspases or granzyme B. Because caspase-3-like caspases or ICE are unlikely to be involved, caspase-2 processing in PC12 cells may occur via autocatalysis. Consistent with this, the D333 site, with the motif VDQQ $D$, was used to generate a fluorogenic substrate for which purified caspase-2 showed great affinity (Talanian et al., 1997). In further support of this idea, dimerization of caspase-2 leads to its activation (Butt et al., 1998).

\section{Role of caspase-2 and caspase-3-like activity in apoptotic cell death after trophic withdrawal}

Our current results confirm previous findings that caspase-2 is necessary for cell death after trophic deprivation in naive and neuronally differentiated PC12 cells (Troy et al., 1997). Additional confirmation has come from studies by Haviv et al. (1998). Recent data indicate that sympathetic neurons cultured from caspase-2 knock-out mice show normal death in response to NGF deprivation (Bergeron et al., 1998). Although these data appear to challenge the role of caspase-2 in developmental cell death attributable to withdrawal of trophic support, they are not necessarily incompatible with our own findings. First, it has been found in many instances that compensatory mechanisms (such as upregulation of other caspases) may occur in knock-out mice. In contrast, our antisense studies provide a model of acute downregulation of caspase-2. Second, both long and short isoforms of caspase- 2 have been described that are derived by alternate splicing (Wang et al., 1994); the former, which corresponds to the protein detected by our antiserum, is proapoptotic, and the latter, which lacks part of the $\mathrm{N}$ terminus of the long form and would not be recognized by our antiserum, is anti-apoptotic (Wang et al., 1994). Bergeron et al. (1998) have deleted the gene encoding both, and, as these authors point out, loss of the anti-apoptotic short form may obscure effects of deletion of the long form, especially in tissues containing both. Of relevance to this, we find by RT-PCR that a transcript encoding the short form is expressed at levels comparable to the long form within neuronally differentiated PC12 cells (our unpublished results). Significantly, our caspase- 2 antisense is directed against the $\mathrm{N}$ terminus that is present only in the long form and therefore would be expected to affect only the proapoptotic, but not the anti-apoptotic, form of the molecule. Together, these considerations suggest that findings with the caspase-2 null mouse are not necessarily in conflict with our observations and that further studies are needed to determine the roles of various caspase- 2 forms in neuronal cell death.

Our data also amplify previous observations about the lack of a role for caspase-3-like activity in cell death in this paradigm (Stefanis et al., 1996). We show here that PC12 cells survive in the presence of induced caspase-3-like activity, provided that caspase-2 expression is downregulated. Thus, induction of caspase-3-like activity is not sufficient to evoke death in our system. This may be true in other paradigms, as well. For example, activation of caspase-3 in stimulated lymphocytes occurs in the absence of apoptosis (Miossec et al., 1997). Such observations raise the cautionary note that induction of caspase-3-like activity cannot necessarily be interpreted to indicate participation of such activity in the apoptotic process. On the other hand, we had noted previously that near-complete inhibition of caspase-3-like activity with low concentrations of zVAD-FMK has minimal effects on survival (Stefanis et al., 1996). Our current data with the more selective caspase-3-like inhibitor DEVD-FMK extend these findings and provide evidence that even with complete inhibition of caspase-3-like activity, the majority of cells still undergo apoptotic cell death. We have also extended these findings to neuronally differentiated PC12 cells and sympathetic neurons. The partial survival effects of DEVD-FMK at the highest concentrations used $(25-100 \mu \mathrm{M})$ are probably related to nonspecific inhibition of caspases that do not belong to the caspase-3-like subfamily. This inhibition may occur at a site downstream of caspase-2 or at the level of another parallel pathway. Thus, caspase-3-like activity is neither sufficient nor necessary for apoptotic death in PC12 cells after trophic deprivation. We have recently extended these findings to embryonic cortical neurons in which apoptotic cell death 
can again be dissociated from caspase-3-like activity (Stefanis, Friedman, Greene, Park, unpublished results).

In conclusion, our current and previous (Stefanis et al., 1996; Troy et al., 1997) results argue that for trophic deprivation of PC12 cells and sympathetic neurons there exist at least two parallel arms of the apoptotic response at the level of the caspases: the caspase- 2 arm is the crucial one leading to death, whereas the caspase-3-like arm is not a determining factor therein (Fig. 7).

\section{REFERENCES}

Allet B, Hochmann A, Martinou I, Berger A, Missoten M, Antonsson B, Sadoul R, Martinou J-C, Bernasconi L (1996) Dissecting processing and apoptotic activity of a cysteine protease by mutational analysis. J Cell Biol 135:479-486.

Batistatou A, Greene LA (1991) Aurintricarboxylic acid rescues PC12 cells and sympathetic neurons from cell death caused by nerve growth factor deprivation: correlation with suppression of endonuclease activity. J Cell Biol 115:461-471.

Batistatou A, Merry DE, Korsmeyer SJ, Greene LA (1993) Bcl-2 affects survival but not neuronal differentiation of PC12 cells. J Neurosci 13:4422-4428.

Bergeron L, Perez GI, Macdonald G, Shi L, Sun Y, Juriscova A, Varmuza S, Latham KE, Flaws JA, Salter JCM, Hara H, Moskowitz MA, Li E, Greenberg A, Tilly JL, Yuan J (1998) Defects in regulation of apoptosis in caspase-2-deficient mice. Genes Dev 12:1304-1314.

Bradford MM (1976) A rapid and sensitive method for quantitation of microgram quantities of protein utilizing the principle of protein dyebinding. Anal Biochem 72:248-254.

Butt AJ, Harvey NL, Parasivam G, Kumar S (1998) Dimerization and autoprocessing of the Nedd2 (caspase-2) precursor requires both the prodomain and the carboxyl-terminal regions. J Biol Chem 273:6763-6768.

Casciola-Rosen L, Nicholson DW, Chong T, Rowan KR, Thornberry NA, Miller DK, Rosen A (1996) Apopain/CPP32 cleaves proteins that are essential for cellular repair: a fundamental principle of apoptotic death. J Exp Med 183:1947-1951.

Darmon AJ, Nicholson DW, Bleackley RC (1995) Activation of the apoptotic protease CPP32 by cytotoxic T-cell-derived granzyme B. Nature 377:446-448.

Deshmukh M, Vasilakos J, Deckwerth TL, Lampe PA, Shivers BD, Johnson Jr EM (1996) Genetic and metabolic status of NGF-deprived sympathetic neurons saved by an inhibitor of the ICE family. J Cell Biol 135:1341-1354.

Duan H, Orth K, Chinnaiyan AM, Poirier GG, Froelich CJ, He W, Dixit VM (1996) ICE-LAP6, a novel member of the ICE/Ced-3 gene family, is activated by the cytotoxic $\mathrm{T}$ cell protease granzyme B. J Biol Chem 271:16720-16724.

Enari M, Talanian RV, Wong WW, Nagata S (1996) Sequential activation of ICE-like and CPP32-like proteases during Fas-mediated apoptosis. Nature 380:723-726.

Erlich HA (1989) PCR Technology. New York: Stockton.

Farinelli SE, Greene LA (1996) Cell cycle blockers mimosine, ciclopirox, and deferoxamine prevent the death of PC12 cells and postmitotic sympathetic neurons after removal of trophic support. J Neurosci 16:1150-1162.

Ferrari G, Yan CYI, Greene LA (1995) $N$-acetylcysteine ( $D$ - and $L$ stereoisomers) prevents apoptotic death of neuronal cells. J Neurosci 15:2857-2866.

Fraser A, Evan G (1996) A licence to kill. Cell 85:781-784.

Greene LA (1978) Nerve growth factor prevents the death and stimulates the neuronal differentiation of clonal PC12 pheochromocytoma cells in serum-free medium. J Cell Biol 78:747-755.

Greene LA, Tischler AS (1976) Establishment of a noradrenergic clonal line of rat adrenal pheochromocytoma cells which respond to nerve growth factor. Proc Natl Acad Sci USA 73:2424-2428.

Harvey KJ, Blomquist JF, Ucker DS (1998) Commitment and effector phases of the physiological cell death pathway elucidated with respect to Bcl-2, caspase, and cyclin-dependent kinase activities. Mol Cell Biol 18:2912-2922.

Harvey NL, Butt AJ, Kumar S (1997) Functional activation of Nedd2/ Ich-1 (caspase-2) is an early process in apoptosis. J Biol Chem 272:13134-13139.
Haviv R, Lindenboim L, Yuan Y, Stein R (1998) Need for caspase-2 in apoptosis of growth-factor-deprived PC12 cells. J Neurosci Res 52:491-497.

Kuida K, Zheng TS, Na S, Kuan C, Yang D, Karasuyama H, Rakic P, Flavell RA (1996) Decreased apoptosis in the brain and premature lethality in CPP32-deficient mice. Nature 384:368-372.

Kumar S, Kinoshita M, Noda M, Copeland NG, Jenkins NA (1994) Induction of apoptosis by the mouse Nedd 2 gene, which encodes a protein similar to the product of the caenorhabditis elegans cell death gene ced-3 and the mammalian IL- $1 \beta$-converting enzyme. Genes Dev 8:1613-1626.

Li H, Bergeron L, Cryns V, Pasternack MS, Zhu H, Lianfa S, Greenberg A, Yuan J (1997) Activation of caspase-2 in apoptosis. J Biol Chem 272:21010-21017.

Margolin N, Raybuck SA, Wilson KP, Chen W, Fox T, Gu Y, Livingston DL (1997) Substrate and inhibitor specificity of interleukin-1 $\beta$ converting enzyme and related caspases. J Biol Chem 272:7223-7228.

Mesner PW, Winters TR, Green SH (1992) Nerve growth factor withdrawal-induced cell death in neuronal PC12 cells resembles that in sympathetic neurons. J Cell Biol 119:1669-1680.

Miller DK, Ayala JM, Egger LA, Raju SM, Yamin T-T, Ding GJ-F, Gaffney EP, Howard AD, Palyha OC, Rolando AM, Salley JP, Thornberry NA, Weidner JR, Williams JH, Chapman KT, Jackson J, Kostura MJ, Limjuco G, Molineaux SM, Mumford RA, Calaycay JR (1993) Purification and characterization of active human interleukin-1 $\beta$ converting enzyme from THP.1 monocytic cells. J Biol Chem 268:18062-18069.

Miossec C, Dutilleul V, Fassy F, Diu-Hercend A (1997) Evidence for CPP32 activation in the absence of apoptosis during $\mathrm{T}$ lymphocyte stimulation. J Biol Chem 272:13459-13462.

Nicholson DW, Ali A, Thornberry NA, Vaillancourt JP, Ding CD, Gallant M, Gareau Y, Griffion PR, Labelle M, Lazebnik YA, Munday NA, Raju SM, Smulson ME, Yamin T-T, Yu VL, Miller DK (1995) Identification and inhibition of the ICE/CED-3 protease necessary for mammalian apoptosis. Nature 376:37-43.

Park DS, Farinelli SE, Greene LA (1996a) Inhibitors of cyclindependent kinases promote survival of post-mitotic neuronally differentiated PC12 cells and sympathetic neurons. J Biol Chem 271:8161-8169.

Park DS, Stefanis L, Yan CYI, Farinelli SE, Greene LA (1996b) Ordering the cell death pathway. Differential effects of bcl-2: an interleukin$1 \beta$-converting enzyme family protease inhibitor, and other survival agents on JNK activation in serum/nerve growth factor-deprived PC12 cells. J Biol Chem 271:21898-21906.

Ramage P, Cheneval D, Chvei M, Graff P, Hemmig R, Heng R, Kocher HP, Mackenzie A, Memmert K, Revesz L, Wishart W (1995) Expression, refolding and autocatalytic proteolytic processing of the interleukin- $1 \beta$-converting enzyme precursor. J Biol Chem 270: 9378-9383.

Rukenstein A, Rydel RE, Greene LA (1991) Multiple agents rescue PC12 cells from serum-free cell death by translation- and transcriptionindependent mechanisms. J Neurosci 11:2552-2563.

Rydel RE, Greene LA (1988) cAMP analogs promote survival and neurite outgrowth in cultures of rat sympathetic and sensory neurons independently of nerve groth factor. Proc Natl Acad Sci USA 85:1257-1261.

Sato N, Milligan CE, Uchiiyama Y, Oppenheim RW (1997) Cloning and expression of the cDNA encoding rat caspase-2. Gene 202:127-132.

Srinivasula SM, Fernandes-Alnemri T, Zangrilli J, Robertson N, Armstrong RC, Wang L, Trapani JA, Tomaselli KJ, Litwack G, Alnemri ES (1996) The Ced-3/Interleukin $1 \beta$ Converting Enzyme-like homolog Mch6 and the lamin-cleaving enzyme $\operatorname{Mch} 2 \alpha$ are substrates for the apoptotic mediator CPP32. J Biol Chem 271:27099-27106.

Stefanis L, Park DS, Yan CYI, Farinelli SE, Troy CM, Shelanski ML, Greene LA (1996) Induction of CPP32-like activity in PC12 cells by withdrawal of trophic support. J Biol Chem 271:30663-30671.

Stefanis L, Troy CM, Qi H, Greene LA (1997) Inhibitors of trypsin-like serine proteases inhibit processing of the caspase Nedd-2 and protect PC12 cells and sympathetic neurons from death evoked by withdrawal of trophic support. J Neurochem 69:1425-1437.

Talanian RV, Quinlan C, Trautz S, Hackett MC, Mankovich JA, Banach D, Ghayur T, Brady KD, Wong WW (1997) Substrate specificities of caspase family proteases. J Biol Chem 272:9677-9682.

Thornberry NA, Bull HG, Calaycay JR, Chapman KT, Howard AD, Kostura MJ, Molineaux SM, Weidner JR, Aunins J, Elliston KO, Ayala 
JM, Casano FJ, Chin J, Ding GJ-F, Egger LA, Gaffney EP, Limjuco G, Palyha OC, Raju SM, Rolando AM, Salley JP, Yamin T-T, Lee TD, Shively JE, MacCross M, Mumford RA, Schmidt JA, Tocci MJ (1992) A novel heterodimeric cysteine protease is required for interleukin-1 $\beta$ processing in monocytes. Nature 356:768-774.

Troy CM, Stefanis L, Prochiantz A, Greene LA, Shelanski ML (1996) The contrasting roles of ICE family proteases and interleukin- $1 \beta$ in apoptosis induced by trophic factor withdrawal and by copper/zinc superoxide dismutase down-regulation. Proc Natl Acad Sci USA 93:5635-5640.

Troy CM, Stefanis L, Greene LA, Shelanski ML (1997) Nedd2 is required for apoptosis after trophic factor withdrawal, but not superoxide dismutase (SOD1) down-regulation, in sympathetic neurons and PC12 cells. J Neurosci 17:1911-1918.

Wang L, Miura M, Bergeron L, Zhu H, Yuan J (1994) Ich-1, an Ice/ced3-related gene, encodes both positive and negative regulators of programmed cell death. Cell 78:739-750.
Woo M, Hakem R, Soengas MS, Duncan GS, Shahinian A, Kagi D, Hakem A, McCurrach M, Khoo W, Kaufman SA, Senaldi G, Howard T, Lowe SW, Mak TW (1998) Essential contribution of caspase 3/CPP32 to apoptosis and its associated nuclear changes. Genes Dev 12:806-819.

Xue D, Shaham S, Horvitz HR (1996) The Caenorhabditis elegans cell-death protein CED-3 is a cysteine protease with substrate specificities similar to those of human CPP32 protease. Genes Dev 10:1073-1083.

Yamin T, Ayala JM, Miler DK (1996) Activation of the native 45-KDa precursor form of interleukin-1-converting enzyme. J Biol Chem 271:13273-13282.

Yuan J, Shaham S, Ledoux S, Ellis HM, Horvitz HR (1993) The $C$. elegans cell death gene ced-3 encodes a protein similar to mammalian interleukin-1 $\beta$-converting enzyme. Cell 75:641-652.

Zhou Q, Salvesen GS (1997) Activation of pro-caspase-7 by serine proteases includes a non-canonical specificity. Biochem J 324:361-364. 